\title{
Oxygen and carbon dioxide concentrations in oxygen tents
}

\author{
B ER N AR D J FREEDMA N \\ From Dulwich Hospital, London, S.E.22
}

In recent years there has been a growing realization that uncontrolled oxygen therapy in patients with emphysema complicated by acute chest infection may be followed by reduced ventilation and thus further elevate an already raised arterial carbon dioxide tension. Hypercapnia may give rise to headache, nausea, profuse sweats, muscular twitchings, drowsiness, and coma $\left(\mathrm{CO}_{2}\right.$ narcosis). The likelihood of hypercapnia is further increased if the inspired gases contain appreciable amounts of expired $\mathrm{CO}_{2}$. Hence it is desirable that apparatus for the administration of oxygen to this type of patient should have the means to supply oxygen $(a)$ at concentrations high enough to raise the arterial $\mathrm{O}_{2}$ tension to adequate levels, yet not so high as to depress ventilation unduly, and (b) with as low a $\mathrm{CO}_{2}$ content as possible.

So far as masks are concerned, an attempt has been made to reduce the $\mathrm{CO}_{2}$ content of inspired gases by increasing the oxygen flow rate; by reducing the dead-space of the mask (M.C. mask ; Catterall, 1960); and by diluting the gases by entrainment of ambient air (Venturi mask ; Campbell, 1960 b). The last method has the further advantage of reducing the oxygen concentration to safe levels.

Oxygen tents are liable, no less than masks, to accumulate undesirable concentrations of $\mathrm{CO}_{2}$, and levels of $1 \%$ to $2 \%$ are commonly reached unless means are adopted to prevent this occurring. In the Oxygenaire Mark $\mathrm{V}$ tent, $\mathrm{CO}_{2}$ may be optionally washed out by the entrainment of ambient air, and the oxygen concentration is simultaneously reduced. This model was accordingly selected for a trial of its efficiency in permitting control of $\mathrm{O}_{2}$ concentration and in maintaining a low $\mathrm{CO}_{2}$ concentration.

\section{MATERIAL AND METHODS}

The tent was used under normal working conditions for five patients suffering from acute infective exacerbations of chronic bronchitis, and for one healthy volunteer. The mattress overlays were covered by non-porous plastic envelopes. Gas samples were aspirated at 10-minute intervals for periods of four to five and a half hours. During this time the zipper was opened for meals, toilet, and nursing procedures. Gas samples were analysed for oxygen with a Beckman analyser, and for carbon dioxide with a modified Haldane analyser $^{1}$ which has an accuracy of $\pm 0.05 \%$. After preliminary 'flushing' at 10 to $121 . / \mathrm{min}$. for 20 minutes the oxygen was run at a fixed rate until sampling showed that oxygen and carbon dioxide percentages in the tent were stable. Similarly, when any change was made, either in the oxygen flow rate or in the entrainment of air, working conditions were maintained without alteration until a new equilibrium was reached. The entrainment of air is referred to in the results as ' $\mathrm{CO}_{2}$ wash-out on', and its absence as ' $\mathrm{CO}_{2}$ wash-out off'. The oxygen consumption of each patient was measured with a Benedict-Roth apparatus as soon as possible after the tent analyses had been completed, and the carbon dioxide output was calculated assuming a respiratory exchange ratio of $0 \cdot 8$. The relative humidity within the tent was measured every 10 minutes with a hair hygrometer. Steps to humidify the oxygen were not taken.

\section{RESULTS}

As the $\mathrm{CO}_{2}$ output of all five patients lay within close range $(178 \mathrm{ml}$. to $197 \mathrm{ml}$. per minute A.T.P.D.) the results have been grouped together in the Table.

Fluctuations in $\mathrm{O}_{2}$ and $\mathrm{CO}_{2}$ concentration could be ascribed to the changing of cylinders, to meals, and to nursing procedures. Switching on the $\mathrm{CO}_{2}$ wash-out produced a rapid fall in $\mathrm{CO}_{2}$ concentration from about $1 \%$ to about $0.5 \%$ in 5 to 10 minutes, followed by a slower decline to $0.2 \%$ to $0.3 \%$ during the ensuing 20 minutes, the actual level reached being independent in practice of the oxygen flow rate.

\footnotetext{
- Aimer Products Ltd.
} 
TABLE

\begin{tabular}{|c|c|c|c|c|c|c|c|c|c|}
\hline \multicolumn{3}{|c|}{$\begin{array}{l}\mathrm{CO}_{2} \text { wash-out off } \\
\mathrm{O}_{2} \text { flow rate }(1 . / \text { min. }) \\
\text { Mean } \mathrm{O}_{2} \text { concentration in tents }(\%) \\
\text { Mean } \mathrm{CO}_{2} \text { concentration in tents }(\%)\end{array}$} & \multicolumn{7}{|c|}{$\begin{array}{l}8 \\
54(\text { range } 50-57) \\
0.96(\text { range } 0 \cdot 8-1 \cdot 1)\end{array}$} \\
\hline $\begin{array}{l}\mathrm{CO}_{2} \text { wash-out on } \\
\mathrm{O}_{2} \text { flow rate }(1 . \text { min. }) \\
\mathrm{O}_{2} \text { concentration }(\%) \\
\mathrm{CO}_{2} \text { concentration }(\%) \\
\text { No. of observations }\end{array}$ & $\begin{array}{l}. \\
\cdots \\
\cdots\end{array}$ & $\begin{array}{l}\cdots \\
\because \\
\because \\
\cdots\end{array}$ & $\begin{array}{c}4 \\
26 \\
0 \cdot 25 \\
1\end{array}$ & $\begin{array}{c}5 \\
25-26 \\
2\end{array}$ & $\stackrel{6}{26-28}$ & $\begin{array}{c}7 \\
27-29 \\
0 \cdot 2-0 \cdot 35 \\
3\end{array}$ & $\begin{array}{c}8 \\
28-31 \\
0 \cdot 25-0 \cdot 45 \\
4\end{array}$ & $\begin{array}{c}9 \\
28 \\
0 \cdot 3 \\
1\end{array}$ & $\begin{array}{c}10 \\
29-31 \\
0 \cdot 2-0 \cdot 4 \\
2\end{array}$ \\
\hline
\end{tabular}

The five patients were of medium build and over 50 years of age. In order to test the tent's response to a higher $\mathrm{CO}_{2}$ output, a heavily built young male volunteer (weight $176 \mathrm{lb}$. (80 kg.), height $5 \mathrm{ft} .11$ in. $(1.79 \mathrm{~m}$.) ) was placed in the tent. At an oxygen flow rate of $81 . / \mathrm{min}$. the gas concentrations in the tent were as follows:$\mathrm{CO}_{2}$ wash-out off :

Oxygen $56 \%$; carbon dioxide $1.6 \%$ $\mathrm{CO}_{2}$ wash-out on:

Oxygen $29.5 \%$; carbon dioxide $0.5 \%$ His $\mathrm{CO}_{2}$ output was $291 \mathrm{ml} / \mathrm{min}$. This was $55 \%$ greater than the mean for the five patients, and the $\mathrm{CO}_{2}$ concentrations in the tent were proportionately higher.

The relative humidity varied between $40 \%$ and $45 \%$ in the six experiments.

\section{DISCUSSION}

An analysis of the factors determining the $\mathrm{O}_{2}$ and $\mathrm{CO}_{2}$ content of tents, and the amount of gaseous interchange between the interior and exterior of tents, has been made by Jahn (1953).

$\mathrm{CO}_{2}$ CONCENTRATIONS When a steady state has been reached (Jahn, 1953)

$$
\mathrm{CO}_{2} \% \text { in tent }=\frac{100 \times \mathrm{C}\left(\mathrm{O}_{2}-21\right)}{79 \mathrm{~F}}
$$

where $\mathrm{C}$ is the rate of $\mathrm{CO}_{2}$ production in $1 . / \mathrm{min}$., $\mathrm{O}_{2}$ is the $\mathrm{O}_{2} \%$ in the tent, and $\mathrm{F}$ is the flow rate of $\mathrm{O}_{2}$ into the tent in $1 . / \mathrm{min}$.

If $\mathrm{CO}_{2}$ production and oxygen flow rate remain constant, it follows from the formula that $\mathrm{CO}_{2} \%$ in the tent varies as $\left(\mathrm{O}_{2}-21\right)$. Taking mean oxygen concentrations in the patients' tents,

with $\mathrm{CO}_{2}$ wash-out off, $\mathrm{O}_{2}=53.5 \%$, and $\left(\mathrm{O}_{2}-21\right)=32 \cdot 5$

with $\mathrm{CO}_{2}$ wash-out on, $\mathrm{O}_{2}=29.5 \%$ and $\left(\mathrm{O}_{2}-21\right)=8 \cdot 5$,

when the $\mathrm{O}_{2}$ flow rate is $81 . / \mathrm{min}$.

Whence there is a predicted fall in $\mathrm{CO}_{2}$ concentration to about one-quarter the initial level after the wash-out is switched on. Other things being equal, the $\mathrm{CO}_{2}$ concentration also varies directly as the patient's $\mathrm{CO}_{2}$ output. In practice, the carbon dioxide concentration is also slightly affected by variations in the rate of diffusion through the bedclothes, and the extent of bellowslike action of the mattress from movements of the patient. The oxygen concentration varies in like manner. For example:

(a) Case 3

$$
\begin{array}{cc}
\mathrm{CO}_{2} \text { wash-out off } & \\
\mathrm{F}=8 & \text { Predicted } \mathrm{CO}_{2} \text { concentration }=0.97 \% \\
\mathrm{C}=0.185 & \text { Measured } \mathrm{CO}_{2} \text { concentration }=0.8 \% \\
\mathrm{O}_{2}=54 & \\
\mathrm{CO}_{2} \text { wash-out on } & \\
\mathrm{F}=8 & \text { Predicted } \mathrm{CO}_{2} \text { concentration }=0.26 \% \\
\mathrm{C}=0.185 & \text { Measured } \mathrm{CO}_{2} \text { concentration }=0.25 \% \\
\mathrm{O}_{2}=30 &
\end{array}
$$

(b) Volunteer

$\mathrm{CO}_{2}$ wash-out off

$$
\mathbf{F}=8
$$

$\mathrm{C}=0.291$

Predicted $\mathrm{CO}_{2}$ concentration $=1,6 \%$

$\mathrm{O}_{2}=56$

Measured $\mathrm{CO}_{2}$ concentration $=1.6 \%$

$\mathrm{CO}_{2}$ wash-out on

$$
\begin{aligned}
& \mathrm{F}=8 \\
& \mathrm{C}=0.291 \\
& \mathrm{O}_{2}=29.5
\end{aligned}
$$

Predicted $\mathrm{CO}_{2}$ concentration $=0.4 \%$ Measured $\mathrm{CO}_{2}$ concentration $=0.5 \%$

$\mathrm{O}_{2}$ CONCEnTRations Campbell (1960a) has shown that, in patients suffering from respiratory failure due to acute chest infection, adequate arterial oxygen saturations may be achieved by administering oxygen in the range $24 \%$ to $35 \%$. Higher oxygen concentrations can be harmful in so far as hypoventilation and a rise in arterial $\mathrm{CO}_{2}$ tension may ensue.

It was not possible under working conditions to complete a full range of measurements for all five patients at each 1-litre increment of flow rate. but where measurements were made on three or four patients at a given flow rate, the variation in $\mathrm{O}_{2}$ concentration was negligible.

It was found possible to obtain predictable oxygen concentrations $( \pm 1 \%)$ in the range $26 \%$ to $30 \%$ by using the $\mathrm{CO}_{2}$ wash-out device in conjunction with oxygen flow rates between 4 and 
$10 \mathrm{l} . / \mathrm{min}$. Undoubtedly the range of oxygen concentrations could be extended in both directions by using flow rates beyond these limits.

VOLUME OF AMBIENT AIR ENTRAINED BY $\mathrm{CO}_{2}$ WASHOUT According to Jahn (1953),

$$
\mathrm{E}=\frac{\mathrm{F}\left(100-\mathrm{O}_{2}\right)}{\mathrm{O}_{2}-21}
$$

where $\mathrm{E}$ is the diffusion exchange in $1 . / \mathrm{min}$., $\mathrm{F}$ is the maintenance oxygen flow rate in $1 . / \mathrm{min}$., and $\mathrm{O}_{2}$ is the oxygen percentage in the tent.

The term 'diffusion exchange' is here defined as the exchange of gases between the interior of the tent and the ambient air, whether by diffusion through the bedclothes, or bellows action resulting from the patient's movements, or the entrainment of air via the $\mathrm{CO}_{2}$ wash-out.

Applying this formula to average measurements given in the Table, it may be calculated that, with an oxygen flow rate of $8 \mathrm{l} . / \mathrm{min}$., 'diffusion exchange' with $\mathrm{CO}_{2}$ wash-out off is $11.41 . / \mathrm{min}$. ; and with $\mathrm{CO}_{2}$ wash-out on it is $66.41 . / \mathrm{min}$. The difference between these rates represents the volume of air entrained by the wash-out mechanism, which is $551 . / \mathrm{min}$. A similar calculation shows that in the volunteer's tent air entrainment was $56 \cdot 3 \mathrm{l} . / \mathrm{min}$.

\section{THE PLACE OF THE TENT IN OXYGEN THERAPY}

It might be thought that recent improvements in the design of masks for the administration of oxygen, previously referred to in the Introduction, have reduced the tent's field of applicability. Objections that have been raised to the use of tents (Ball, 1961; Miller, 1962) are expense, trouble of maintenance, and difficulties of access to the patient for feeding, nursing procedures, and physiotherapy. Some patients feel oppressed, hot, and sweaty despite adequate control of temperature and humidity.

Undoubtedly, a suitable mask is the first choice, if its design will eliminate rebreathing, and if it will give predictable oxygen concentrations.

It cannot be denied, however, that some patients are so restless, fidgety, confused or intolerant of masks that this method of administration becomes impracticable. With these patients the mask (or intra-nasal catheter) soon becomes displaced, thus losing efficiency, or it may even be thrown aside. There is also the occasional male patient who tinkers with his giving-set, turning the flow high or low, on or off, as and when he fancies, regard- less of requirements. For all these patients a properly set-up tent offers a degree of reliability in the maintenance of suitable gas concentrations $\frac{\bar{\omega}}{\vec{D}}$ that is unobtainable with masks. When this is $\stackrel{\varnothing}{\varrho}$ paramount, the trouble and expense are a small price to pay. The discomfort experienced by some patients in tents is usually due to a high $(1 \%$ to $2 \%) \mathrm{CO}_{2}$ content, and the feeling of stuffiness, $\vec{\omega}$ sweating, headache, and restlessness, wrongly ${ }^{\circ}$ ascribed to heat and humidity, are due to the $\overrightarrow{\vec{x}}$ ensuing hypercapnia. In fact, the temperature and relative humidity within the tent may be demon- 0 strably the same as that in the ambient air, or even $i$ cooler and drier. All these distressing symptoms are eliminated by the $\mathrm{CO}_{2}$ wash-out.

\section{SUMMARY}

Patients with respiratory failure due to emphy- $\frac{\Phi}{3}$ sema complicated by acute chest infection may뮤 suffer from $\mathrm{CO}_{2}$ retention. In these circumstances inhalation of expired $\mathrm{CO}_{2}$ in the course of oxygen $\vec{\ominus}$ therapy aggravates the $\mathrm{CO}_{2}$ retention. $\mathrm{CO}_{2}$ con- + centrations of $1 \%$ to $2 \%$ may be encountered in oxygen tents unless means are adopted to effect? a reduction. High oxygen concentrations may depress ventilation and further aggravate $\mathrm{CO}_{2} \stackrel{\mathrm{O}}{2}$ retention.

The Oxygenaire Mark V tent, which incor $\stackrel{\varrho}{\Rightarrow}$ porates a $\mathrm{CO}_{2}$ 'wash-out' device, was tested foro응 efficiency in reducing $\mathrm{CO}_{2}$ concentrations: reduction to about one-quarter of pre-existing levels was found. Predictable $\mathrm{O}_{2}$ concentrations between $26 \%$ and $30 \%$ were obtained using the washout in conjunction with various $0_{2}$ flow-rates.

The place of the tent in oxygen therapy is: discussed.

Thanks are due to the S.E. Metropolitan Regionalô Hospital Board for apparatus, to Messrs. Oxygen aire Ltd. for the loan of a Beckman oxygen analyser? and to both bodies for technical assistance; also to Mr. R. E. Jahn, of the Pioneer Department, Britisho Oxygen Co. Ltd., and to Mr. P. B. Earnshaw, of the Aerodynamics Department, Royal Aircraft Establish No ment, for advice.

\section{REFERENCES}

Ball, J. A. C. (1961). The administration of oxygen. Lancet, 1, 591. Campbell, E. J. M. (1960a). Respiratory failure. The relation betweer oxygen concentrations of inspired air and arterial blood. Ibid 2,10 .

(1960b). A method of controlled oxygen administration whiciad reduces the risk of carbon-dioxide retention. Ibid., $2,12$. Catterall, M. (1960). A rew mask fcr delivering oxygen or othef gases. Brit. med. J., 1, 1941.

Jahn, R. E. (1953). An examination of oxygen and carbon dioxide concentrations in adult oxygen tents. B it. J. Anaesth., 25, 188 . O

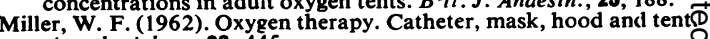
Anesthesiology, 23, 445 . 